\title{
COMENTARIO A LA LEY 15/2015, DE 2 DE JULIO, DE LA JURISDICCIÓN VOLUNTARIA.
}

Dra. Laura Gázquez Serrano

Prof. Titular Derecho Civil Universidad de Granada

Email:1gazquez@ugr.es

RESUMEN: El artículo trata, a modo de resumen, sobre las modificaciones de determinados artículos del Código Civil por parte de la Ley 15/2015 de 2 de julio de la jurisdicción voluntaria. Se realiza un análisis comparando la anterior legislación con la nueva aportando las principales novedades

PALABRAS CLAVE: Jurisdicción voluntaria, Código civil, persona, familia

\begin{abstract}
The article is, in summary, on amendments to certain articles of the Civil Code by Law 15/2015 of July 2 voluntary jurisdiction. analysis is performed by comparing the previous legislation providing new major developments
\end{abstract}

KEY WORDS: Voluntary Jurisdiction, Civil Code, person, family 
Artículos modificados: 47, 48, 49, 51, 52, 53, 55, 56, 57, 58, 60, 62, 63, 65, 73, 81, 82, $83,84,87,89,90,95,97,99,100,107,156,158,167,173,176,177,181,183,184$, 185, 186, 187, 194, 196, 198, 219, 249, 256, 259, 263, 264, 265, 299 bis, 300, 302, 314, 681, 689, 690, 691, 692, 693, 703, 704, 712, 713, 714, 718, 756, 834, 835, 843, 899, 905, 910, 945, 956, 957, 958, 1005, 1008, 1011, 1014, 1015, 1017, 1019, 1020, 1024, $1030,1033,1057,1060,1176,1178,1180,1377,1389,1392$ у $1442^{1}$.

\section{Introducción.}

\section{Artículo 82 del Código Civil.}

Redacción anterior: Sin contenido derogado por Ley 15/2005, de 8 de julio

Redacción actual: 1. Los cónyuges podrán acordar su separación de mutuo acuerdo transcurridos tres meses desde la celebración del matrimonio mediante la formulación de un convenio regulador ante el Secretario judicial o en escritura pública ante Notario, en el que, junto a la voluntad inequívoca de separarse, determinarán las medidas que hayan de regular los efectos derivados de la separación en los términos establecidos en el artículo 90. Los funcionarios diplomáticos o consulares, en ejercicio de las funciones notariales que tienen atribuidas, no podrán autorizar la escritura pública de separación.

Los cónyuges deberán intervenir en el otorgamiento de modo personal, sin perjuicio de que deban estar asistidos por Letrado en ejercicio, prestando su consentimiento ante el Secretario judicial o Notario. Igualmente los hijos mayores o menores emancipados

\footnotetext{
${ }^{1}$ La finalidad de estas modificaciones es la adaptación de sus preceptos a las nuevas previsiones de la Ley, que afectan, entre otros, a la determinación de la concurrencia de los requisitos para contraer matrimonio y su celebración, a la regulación de la separación o divorcio de mutuo acuerdo de los cónyuges sin hijos menores de edad fuera del ámbito judicial atribuyendo al Secretario judicial y al Notario las funciones que correspondían al Juez, contenido del convenio. Adopción, ausencia y fallecimiento, testamentos y herencia, introduciendo una nueva regulación de las causas de indignidad para heredar y para ser testigo en el otorgamiento de los testamentos.
} 
deberán otorgar el consentimiento ante el Secretario judicial o Notario respecto de las medidas que les afecten por carecer de ingresos propios y convivir en el domicilio familiar.

2. No será de aplicación lo dispuesto en este artículo cuando existan hijos menores no emancipados o con la capacidad modificada judicialmente que dependan de sus progenitores.

\section{Artículo 83 del Código Civil}

Redacción anterior: La sentencia de separación produce la suspensión de la vida común de los casados, y cesa la posibilidad de vincular bienes del otro cónyuge en el ejercicio de la potestad doméstica.

Redacción actual: La sentencia o decreto de separación o el otorgamiento de la escritura pública del convenio regulador que la determine producen la suspensión de la vida común de los casados y cesa la posibilidad de vincular bienes del otro cónyuge en el ejercicio de la potestad doméstica.

Los efectos de la separación matrimonial se producirán desde la firmeza de la sentencia o decreto que así la declare o desde la manifestación del consentimiento de ambos cónyuges otorgado en escritura pública conforme a lo dispuesto en el artículo 82. Se remitirá testimonio de la sentencia o decreto, o copia de la escritura pública al Registro Civil para su inscripción, sin que, hasta que esta tenga lugar, se produzcan plenos efectos frente a terceros de buena fe.

\section{Artículo 84 del Código Civil}

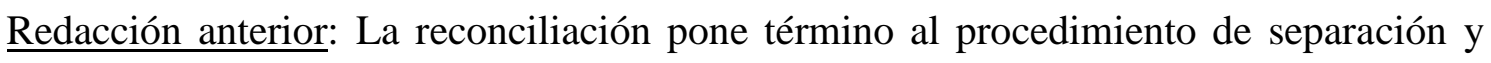
deja sin efecto ulterior lo resuelto en él, pero ambos cónyuges separadamente deberán ponerlo en conocimiento del Juez que entienda o haya entendido en el litigio. 
Ello no obstante, mediante resolución judicial, serán mantenidas o modificadas las medidas adoptadas en relación a los hijos, cuando exista causa que lo justifique

Redacción actual: La reconciliación pone término al procedimiento de separación y deja sin efecto ulterior lo resuelto en él, pero ambos cónyuges separadamente deberán ponerlo en conocimiento del Juez que entienda o haya entendido en el litigio. Ello no obstante, mediante resolución judicial, serán mantenidas o modificadas las medidas adoptadas en relación a los hijos, cuando exista causa que lo justifique.

Cuando la separación hubiere tenido lugar sin intervención judicial, en la forma prevista en el artículo 82, la reconciliación deberá formalizase en escritura pública o acta de manifestaciones.

La reconciliación deberá inscribirse, para su eficacia frente a terceros, en el Registro Civil correspondiente.

\section{Artículo 87 del Código Civil}

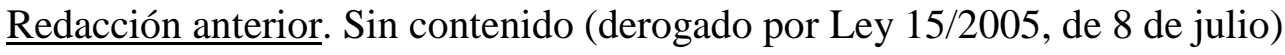

Redacción actual: Los cónyuges también podrán acordar su divorcio de mutuo acuerdo mediante la formulación de un convenio regulador ante el Secretario judicial o en escritura pública ante Notario, en la forma y con el contenido regulado en el artículo 82, debiendo concurrir los mismos requisitos y circunstancias exigidas en él. Los funcionarios diplomáticos o consulares, en ejercicio de las funciones notariales que tienen atribuidas, no podrán autorizar la escritura pública de divorcio.

\section{Artículo 89 del Código Civil.}

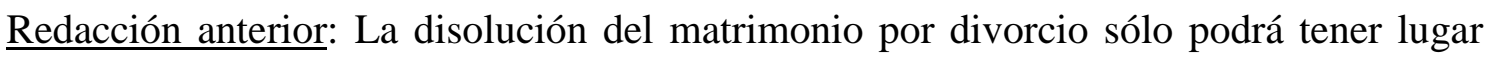
por sentencia que así lo declare y producirá efectos a partir de su firmeza. No perjudicará a terceros de buena fe sino a partir de su inscripción en el Registro Civil. 
Redacción actual: Los efectos de la disolución del matrimonio por divorcio se producirán desde la firmeza de la sentencia o decreto que así lo declare o desde la manifestación del consentimiento de ambos cónyuges otorgado en escritura pública conforme a lo dispuesto en el artículo 87. No perjudicará a terceros de buena fe sino a partir de su respectiva inscripción en el Registro Civil.

\section{Comentario artículos del Código Civil modificados: 82, 83, 84, 87 y 89}

La modificación del Código Civil tiene por objeto la adaptación de muchos de sus preceptos a las nuevas previsiones contenidas en esta Ley, ${ }^{2}$ al tiempo que se introducen modificaciones que afectan a la determinación de la concurrencia de los requisitos para contraer matrimonio y su celebración, así como a la regulación de la separación o divorcio de mutuo acuerdo de los cónyuges sin hijos menores de edad fuera del ámbito judicial, atribuyendo al Secretario judicial ${ }^{3}$ y al Notario las funciones que hasta ahora correspondían al $\mathrm{Juez}^{4}$ y que también conllevan una reforma de la

\footnotetext{
${ }^{2}$ La previsión de que la Ley entrará en vigor a los 20 días de su publicación oficial en el BOE, con determinadas excepciones, así, en materia de: 1. Adopción. 2. Subastas judiciales voluntarias y notariales.3. Modificaciones de los artículos del CC de la LRC, atinentes a la tramitación y celebración matrimonios por Notarios y Secretarios Judiciales, que entrarán en vigor el 30 de junio de 2017. La posibilidad de tramitar el acta previa queda pospuesta hasta el día 30 de junio del 2017. Hasta entonces el expediente previo se seguirá tramitando por el encargado del Registro Civil. Pero la posibilidad de celebrar el matrimonio y el consiguiente otorgamiento de la escritura de formalización del consentimiento matrimonial podrá tener lugar desde la entrada en vigor de la Ley de Jurisdicción Voluntaria (a los veinte días de su publicación en el BOE) Cf. Rivero Sánchez Covisa. F.J. La intervención del notario en el matrimonio conforme a la nueva ley de jurisdicción voluntaria. Revista Bimestral del Ilustre Colegio Notarial de Madrid 10 de julio de 2015.
}

${ }^{3}$ La Ley Orgánica 7/2015, de 21 de julio, por la que se modifica la Ley Orgánica 6/1985, de 1 de julio, del Poder Judicial (en adelante LOPJ) y que ha entrado en vigor el 1 de octubre de 2015, modifica el artículo 440 de la LOPJ sustituyendo la denominación de Secretarios judiciales por la de Letrados de la Administración de Justicia, estableciendo la Disposición Adicional Primera de la LO 7/2015 que a partir de la entrada en vigor de la misma, todas las referencias que se contengan en la LOPJ, así como en otras normas jurídicas, a Secretarios judiciales deberán entenderse hechas a Letrados de la Administración de Justicia.

\footnotetext{
${ }^{4}$ Se atribuye, con gran acierto, un buen número de expedientes a otros operadores jurídicos especialmente cualificados, como lo son los Secretarios judiciales, los Notarios y los Registradores. La atribución a estos profesionales del Derecho de la resolución de expedientes referidos a materias de su concreta especialidad, que no presentan conflicto entre las partes, nos parece una óptima medida de racionalización del sistema, redistribución de los recursos, modernización de la Justicia y economía procesal. Cf. Calaza López, S. Una nueva jurisdicción voluntaria de personas y de familia (1) Práctica de Tribunales, $\mathrm{N}^{\circ} 116$, Septiembre-Octubre 2015, Editorial LA LEY LA LEY 5178/2015
} 
Ley 20/2011, de 21 de julio, del Registro Civil $^{5}$, de la Ley de Enjuiciamiento Civil y de la Ley del Notariado ${ }^{6}$. La atribución de nuevas competencias a los notarios es una tendencia que se ha producido en otros países iberoamericanos de la que fue pionera Cuba: Ecuador, Brasil, Perú, y Colombia. México recientemente ha dado el primer paso en el estado de Sinaloa ${ }^{7}$.

Aparece prevista en el Código Civil, fundamentalmente en los arts. 82 (separación), 87 (divorcio) y 90 (convenio regulador), en la Ley de Enjuiciamiento Civil en su artículo 777.10 y en la Ley del Notariado en el artículo $54^{8}$.

Las modificaciones en materia de matrimonio también conllevan ajustes que se realizan en la Ley 24/1992, de 10 noviembre, por la que se aprueba el Acuerdo de

\footnotetext{
${ }^{5}$ La finalidad de estas modificaciones es la adaptación de sus preceptos a las nuevas previsiones de la Ley, en especial, la nueva forma de celebración del matrimonio, inscripciones del régimen económico y de la separación, nulidad y divorcio.

${ }^{6}$ La finalidad de estas modificaciones es la adaptación de sus preceptos a las nuevas previsiones de la Ley, en especial: escritura pública de separación matrimonial y divorcio, cuando no tuvieren hijos menores no emancipados o con la capacidad modificada judicialmente que dependan de ellos, formalizando un convenio en escritura pública asistidos de Letrado y con sujeción a lo dispuesto en el Código Civil

7 Con ello España se suma a una corriente internacional que en los últimos años ha tratado de desjudicializar materias en las que no existe conflicto o contienda que dirimir. Cf. Cavallé Cruz, A. Viabilidad del divorcio del mutuo acuerdo ante notario. EL NOTARIO DEL SIGLO XXI - MARZO-
}

\section{ABRIL 2012 / N²}

\footnotetext{
${ }^{8}$ Muy importante es también la nueva regulación que del acta o expediente previo a la celebración del matrimonio recoge el Código Civil, encomendando su tramitación al Secretario judicial, Notario, al Encargado del Registro Civil o al Cónsul o funcionario diplomático o consular Encargado del Registro Civil en el extranjero, al tiempo que la celebración del mismo podrá tener lugar ante el Secretario judicial, Notario, funcionario diplomático o consular, Juez de Paz y Alcalde o concejal en el que este delegue. Todo ello se enmarca igualmente en el proceso de diversificación de los elementos personales ante los que se lleva a efecto la autorización de determinados actos, que permite la concentración de la Administración de Justicia a la labor fundamental que la Constitución les atribuye de juzgar y ejecutar lo juzgado. El artículo 54 de la LN también modificado por la LJV dice: «1. Los cónyuges, cuando no tuvieren hijos menores no emancipados o con la capacidad modificada judicialmente que dependan de ellos, podrán acordar su separación matrimonial o divorcio de mutuo acuerdo, mediante la formulación de un convenio regulador en escritura pública. Deberán prestar su consentimiento ante el Notario del último domicilio común o el del domicilio o residencia habitual de cualquiera de los solicitantes. 2. Los cónyuges deberán estar asistidos en el otorgamiento de la escritura pública de Letrado en ejercicio. 3. La solicitud, tramitación y otorgamiento de la escritura pública se ajustarán a lo dispuesto en el Código Civil y en esta ley».
} 
Cooperación del Estado con la Federación de Entidades Religiosas Evangélicas de España, la Ley 25/1992, de 10 de noviembre, por la que se aprueba el Acuerdo de Cooperación del Estado con la Federación de Comunidades Israelitas de España y la Ley 26/1992, de 10 de noviembre, por la que se aprueba el Acuerdo de Cooperación del Estado con la Comisión Islámica de España. Además, en relación con la Ley 25/1992, de 10 de noviembre, se atiende la petición dirigida por esta Federación para que su denominación pase a ser la de Federación de Comunidades Judías de España 9 .

Con la redacción actual se permite la separación o divorcio de mutuo acuerdo de los cónyuges sin hijos menores de edad, o personas con la capacidad judicialmente modificada, fuera del ámbito judicial ${ }^{10}$, atribuyendo al Secretario judicial y al Notario las funciones que hasta ahora correspondían al $\mathrm{Juez}^{11}$ y que también conllevan una reforma de la Ley 20/2011, de 21 de julio, del Registro Civil, de la Ley de Enjuiciamiento Civil y de la Ley del Notariado. Entiendo por tanto que a raíz de la reforma son tres los procedimientos para obtener la separación o divorcio: ante el juez, ante el secretario judicial y ante el notario ${ }^{12}$. Es decir, dado el carácter dispositivo de los

\footnotetext{
${ }^{9}$ Igualmente, y en atención al pluralismo religioso existente en la sociedad española, y teniendo en cuenta que al día de hoy han sido reconocidas con la declaración de notorio arraigo, se contempla en el Código Civil a estos colectivos el derecho a celebrar matrimonio religioso con efectos civiles, equiparándose al resto de confesiones que ya disfrutaban de esta realidad.

${ }^{10}$ Como se ha afirmado, la desjudicialización opera en una doble vía: por un lado, entregando asuntos a Notarios (como los relativos a testamentos, consignación, celebración de subastas voluntarias) y Registradores Mercantiles (muchos de los societarios: convocatorias a juntas generales, nombramiento de auditor, liquidador e interventor, reducción de capital social, convocatoria de asamblea de obligacionistas), por otro, atribuyendo a los Secretarios Judiciales el conocimiento de muchos expedientes (especialmente los relativos a sucesiones, obligaciones y derechos reales) en detrimento de los Jueces. De hecho, éstos sólo siguen siendo resolviendo los procedimientos de jurisdicción voluntaria relativos al Derecho de persona (filiación no matrimonial, adopción, autorizaciones en caso de menores y personas con capacidad disminuida) y al Derecho de familia (impedimentos, disensos en casos de patria potestad o entre cónyuges). Cf. Banacloche, Palao. J La intervención de abogado y procurador en la nueva ley de jurisdicción voluntaria. La Ley 503372015.
}

${ }^{11}$ La novedad fundamental en lo que atañe a la separación y al divorcio viene constituida, sin duda, por la posibilidad de que los cónyuges, concurriendo determinadas circunstancias, puedan instar la separación o la disolución del matrimonio ante funcionarios distintos de aquellos que tienen atribuida la potestad jurisdiccional. La propia exposición de motivos de la Ley, se refiere a lo anterior en los siguientes términos: “...al tiempo que se introducen modificaciones que afectan a la regulación de la separación o divorcio de mutuo acuerdo de los cónyuges sin hijos menores de edad fuera del ámbito judicial, atribuyendo al Secretario judicial y al Notario las funciones que hasta ahora correspondían al Juez..."

12 El hecho que los cónyuges puedan acudir a la vía judicial o notarial respeta el principio de tutela judicial efectiva y el derecho a un proceso sin las dilaciones indebidas. Cf. Ludeña Beníez. O.D. Alternatividad o exclusividad de profesionales en la tramitación y decisión de los expedientes de 
artículos 82 y 87, los cónyuges, si así lo estiman oportuno, podrán tramitar su divorcio o separación "de mutuo acuerdo" ante órganos jurisdiccionales. ${ }^{13}$

Por tanto la Ley que aquí comentamos asigna al notario, junto con el juez el secretario judicial o funcionario local, numerosas competencias en expedientes familiares no contenciosos, que tiene como consecuencia más inmediata una cierta desjudicialización de los asuntos familiares reservando la intervención del juez solo para los casos en los que se considera que es realmente necesaria, para asegurar la defensa de los derechos fundamentales de personas vulnerables como los menores o personas con capacidad de obrar modificada ${ }^{14}$.

Por tanto, puesto que dos personas podrán casarse expresando su consentimiento matrimonial ante Notario, también deberían poder hacer otro tanto, expresando un consentimiento de signo opuesto, para separarse o divorciarse.

Puede que el motivo que lleve a las partes a decidir si acuden al notario o al secretario judicial dependerá además de la posible celeridad del trámite ${ }^{15}$, también de los costes que lleve aparejado. Respecto de los costes en vía notarial habrá que estar a lo dispuesto en la disposición adicional cuarta de la Ley de Jurisdicción Voluntaria, que

jurisdicción voluntaria: una discusión parlamentaria y doctrinal hasta la aprobación de la Ley 15/2015, de 2 de julio. Práctica de Tribunales, $N^{\circ}$ 116, Septiembre-Octubre 2015, Editorial LA LEY. La Ley $185 / 2015$.

13 La opción por la alternatividad, con carácter preferente, entre secretarios judiciales, notarios y registradores, conforme a las enmiendas aprobadas en la Comisión de Justicia del Congreso, en atención a que la idea de las competencias compartidas, supone un beneficio para el ciudadano que podrá optar por acudir, con análogo grado de seguridad jurídica, ante la Oficina Judicial, presidida por el secretario judicial, de forma gratuita, o hacerlo ante un notario o registrador, cuando considere que el pago del arancel se vea compensado por razones de celeridad, proximidad o especialidad. Cf. Fernández de Buján A. La Ley de jurisdicción voluntaria en el umbral de su aprobación Actualidad Jurídica Aranzadi num 90818 de junio de 2015.

${ }^{14}$ Cf. Espinosa de Soto, J.L. Tendencias actuales en derecho de familia. Escritura pública. Número 95 septiembre-octubre de 2015.

${ }^{15}$ Se ha afirmado que en los supuestos en que los cónyuges no tengan hijos menores no emancipados o con la capacidad modificada judicialmente que dependan de sus progenitores y carezcan de un patrimonio relevante, la vía notarial parece que sea el medio más idóneo y rápido para obtener la separación o divorcio de mutuo acuerdo. Cf. Sánchez García J.M. La alternatividad entre los letrados de la administración de justicia, notarios y registradores, en los supuestos de separación o divorcio de mutuo acuerdo, obligaciones y expedientes de conciliación, en la ley de jurisdicción voluntaria. Revista de DerechovLexNúm.136,Septiembre,2015 
respecto de los aranceles notariales y registrales prevé que el Gobierno aprobará en el plazo de tres meses a contar desde su publicación en el «Boletín Oficial del Estado (3 de julio de 2015) los aranceles correspondientes a la intervención de los Notarios y Registradores de la Propiedad y Mercantiles respecto de los asuntos, actas, escrituras públicas, expedientes, hechos y actos inscribibles para los que resulten competentes conforme a lo dispuesto en la Ley de Jurisdicción Voluntaria. El decreto del Secretario judicial no devengará impuestos por actos jurídicos documentados, al contrario que la escritura notarial que si puede estar sujeta el devengo del mismo ${ }^{16}$.

Según los artículos 82 y 87 del Código Civil, los funcionarios diplomáticos y consulares de España en el extranjero no podrán autorizar la escritura de divorcio o de separación. La competencia notarial solo abarca el divorcio y la separación. No se extiende a la nulidad matrimonial, aunque existiera acuerdo de los cónyuges sobre la misma.

Así pues, una de las grandes reformas del Código Civil operadas por la nueva ley de jurisdicción voluntaria es la que afecta a la separación y divorcio, pues a partir de ahora se permite que dándose determinados requisitos (transcurridos tres meses ${ }^{17}$, como exige el artículo 82 del Código, que no haya hijos menores de $\operatorname{edad}^{18}$ o con la capacidad modificada judicialmente tal y como se desprende del párrafo primero del articulo 81 del Código Civil y lógicamente mutuo acuerdo de los cónyuges, tal y como disponen los artículos 82.1 y 87 del Código Civil), ambos puedan tramitarse no solo ante el juez, sino también ante el secretario judicial y el notario. Será Notario

\footnotetext{
${ }^{16}$ Cf. Sánchez García J.M. La alternatividad entre los letrados de la administración de justicia, notarios y registradores, en los supuestos de separación o divorcio de mutuo acuerdo, obligaciones y expedientes de conciliación, en la ley de jurisdicción voluntaria Revista de Derecho vLex - Núm. 136, Septiembre 2015

${ }^{17}$ Para que sea posible la separación o el divorcio de mutuo acuerdo deben haber transcurrido al menos tres meses desde el matrimonio (artículos 82 y 87 del Código Civil)

${ }^{18}$ Se ha puesto en duda la eficacia de no permitir la separación o divorcio ante notario si hay hijos menores de edad, pues se entiende que aboca a un proceso judicial obligatorio, que debido a la falta de recursos materiales de la administración de justicia, no alivia el problema, sino que lo agrava. Para permitir esta opción sería conveniente la presencia de dos abogados al objeto de que cada uno asesore parcialmente a cada cónyuge, y les ayude en la formación de su voluntad, no ya por proteger a los cónyuges, sino a los hijos. Cf. Rosales de Salamanca Rodríguez. F. ¿Divorcio ante notario habiendo hijos menores? Mayo 2015.
} 
competente el del último domicilio común de los cónyuges o el del domicilio de cualquiera de los solicitantes ${ }^{19}$.

Por tanto tenemos que afirmar que la separación necesariamente tendrá que ser judicial siempre que existan hijos menores de edad, no emancipados o con la capacidad modificada judicialmente aún en el supuesto que existiera mutuo acuerdo entre los cónyuges. Que además es el tenor literal de lo dispuesto en el artículo 81 del Código Civil: la separación deberá decretarse judicialmente cuando existan hijos menores no emancipados o con la capacidad modificada judicialmente que dependan de sus progenitores. En el caso de disolución por divorcio la regulación que contiene el artículo 87 es idéntica, de tal modo que existiendo hijos en las circunstancias anteriormente descritas, la disolución por divorcio (ya de mutuo acuerdo, ya contencioso) precisará en todo caso de la intervención de los órganos jurisdiccionales.

El artículo 83 del Código Civil exige, sin excepción, que el notario remita copia de la escritura pública al Registro Civil, pero no como requisito constitutivo del divorcio o de la separación, sino de eficacia frente a terceros de buena fe. La separación y el divorcio por tanto no producirá plenos efectos frente a terceros de buena fe, hasta que se proceda a su inscripción.

Así pues, el procedimiento será distinto según la separación o divorcio se realice ante el secretario judicial o ante el notario ${ }^{20}$. Si la separación judicial o divorcio de mutuo acuerdo se planteara ante el Secretario Judicial, será preciso hacerlo mediante la formulación de un convenio regulador. El art. 777.10 LEC establece que, inmediatamente después de la ratificación, este dictará Decreto pronunciándose sobre el citado convenio y formalizando la propuesta. Este Decreto no será recurrible ${ }^{21}$.

\footnotetext{
${ }^{19}$ Coincide con lo previsto en el artículo 769.2 LEC para el procedimiento judicial de separación o divorcio de mutuo acuerdo, según la redacción dada al mismo por la Ley de Jurisdicción Voluntaria, aunque en este artículo de la LEC se hable únicamente de domicilio común o del domicilio de cualquiera de los cónyuges, y no se emplee la alternativa domicilio-residencia habitual, que en realidad coincide con el domicilio. salvo en supuestos excepcionales de domicilio legal.

${ }^{20}$ Las nuevas competencias asignadas a los secretarios judiciales a los notarios es posible gracias a su condición de funcionarios públicos, y el hecho de ser titulares de la fe pública judicial y extrajudicial.

21 Artículo 777.10 LEC Si la competencia fuera del Secretario judicial por no existir hijos menores no emancipados o con la capacidad modificada judicialmente que dependan de sus progenitores, inmediatamente después de la ratificación de los cónyuges ante el Secretario judicial, este dictará
} 
En estos casos, la LEC exige la ratificación de la voluntad de los cónyuges ante el Secretario competente. Pues bien, la aplicación del párrafo tercero del art. 777 de la_Ley de Enjuiciamiento Civil, que no ha sido modificado, comporta que el Secretario Judicial competente deba citar a los cónyuges dentro de los tres días siguientes para que ratifiquen por separado su petición; producida ésta, el Secretario judicial ha de dictar el decreto pronunciándose sobre el mismo. La ratificación constituye un acto en virtud del cual las partes de forma solemne admiten ante el órgano competente su voluntad de separarse o divorciarse y su íntegra conformidad a los pactos y acuerdos contenidos en el convenio regulador aportado. La exigencia de la ratificación separada de los cónyuges obedece a la necesidad de garantizar la expresión libre de la voluntad, ofreciéndoseles la posibilidad de manifestar sin condicionante alguno la íntima decisión adoptada respecto a la separación o el divorcio y sus efectos ${ }^{22}$.

\section{Si se realizara ante Notario, los cónyuges podrán acordarlo mediante la} formulación de un convenio regulador en escritura pública ${ }^{23}$. Tal y como dispone el artículo 54 de la Ley del Notariado, en vigor desde el 23 de julio de $2015^{24}$. La

decreto pronunciándose, sobre el convenio regulador. El decreto que formalice la propuesta del convenio regulador declarará la separación o divorcio de los cónyuges. Si considerase que, a su juicio, alguno de los acuerdos del convenio pudiera ser dañoso o gravemente perjudicial para uno de los cónyuges o para los hijos mayores o menores emancipados afectados, lo advertirá a los otorgantes y dará por terminado el procedimiento. En este caso, los cónyuges solo podrán acudir ante el Juez para la aprobación de la propuesta de convenio regulador. El decreto no será recurrible. La modificación del convenio regulador formalizada por el Secretario judicial se sustanciará conforme a lo dispuesto en este artículo cuando concurran los requisitos necesarios para ello".

${ }^{22}$ Cf. Pérez de Ontiveros Baquero, C. Separación y divorcio matrimonial: una lectura inicial tras la modificaciones introducidas por Ley 15/2015 de jurisdicción voluntaria. Aranzadi Civil- Mercantil número 10/2015.

${ }^{23}$ Por ser una vía alternativa a la judicial, lo que puede contenerse o no en el convenio regulador y en la escritura de disolución del régimen económico matrimonial es idéntico a la vía judicial, es decir, se extingue el régimen económico matrimonial, y habrá las correspondientes adjudicaciones (conforme a las reglas del REM que corresponda al matrimonio), y, además, por ser en escritura, frente a cuando es en vía judicial, también podrán adjudicarse bienes privativos concretos, sea para satisfacerse excesos de adjudicación o para cumplir con determinadas obligaciones legales. Cf. Serrano de Nicolás, A. La ley de jurisdicción voluntaria: aspectos de mayor relevancia notarial. La Ley 5060/2015.

24 Artículo 54 Ley del notariado: “1. Los cónyuges, cuando no tuvieren hijos menores no emancipados o con la capacidad modificada judicialmente que dependan de ellos, podrán acordar su separación matrimonial o divorcio de mutuo acuerdo, mediante la formulación de un convenio regulador en escritura pública. Deberán prestar su consentimiento ante el Notario del último domicilio común o el del domicilio o residencia habitual de cualquiera de los solicitantes 2. Los cónyuges deberán estar asistidos en el otorgamiento de la escritura pública de Letrado en ejercicio. 3. La solicitud, tramitación y otorgamiento de la escritura pública se ajustarán a lo dispuesto en el Código Civil y en esta ley". 
necesidad de constar en escritura pública es consecuencia de hallarnos ante la prestación de un consentimiento negocial. El mencionado convenio regulador formará parte de la escritura pública, si bien podrá consistir en una elevación a público de lo estipulado previamente $^{25}$. El contenido de la escritura necesariamente será la declaración de los cónyuges de su intención de separarse o divorciarse, y la incorporación del convenio regulador.

Con respecto a qué función va a desempeñar el notario en la tramitación de la separación o divorcio, lógicamente no podrá adoptar medidas que sean competencia judicial, por lo que en definitiva se tratará de homologar o no, lo propuesto por las partes, siempre y cuando se considere equilibrado para ambas y por supuesto, ajustado a la legalidad ${ }^{26}$. Si el notario considera la existencia de desequilibrio o que el acuerdo puede ser perjudicial para los cónyuges, dictará una diligencia aprobando o denegando.

En este punto encontramos una notable diferencia con respecto de la regulación anterior pues como se ha puesto de manifiesto, si algunas de las cláusulas del convenio resulta especialmente perjudicial o desequilibrada para alguna de las partes, s se trata de tramitación judicial, cabrá formular nuevas propuestas hasta que, finalmente, recaiga la homologación judicial (art.90.2, segundo párrafo del Código Civil), mientras que ahora esta posibilidad se excluye expresamente pues, cuando el Secretario judicial o Notario “considerasen que, a su juicio, alguno de ellos (de los acuerdos) pudiera ser dañoso o gravemente perjudicial para. . . lo advertirán a los otorgantes y darán por terminado el expediente. En este segundo caso, los cónyuges sólo podrán acudir ante el Juez para la aprobación de la propuesta de convenio regulador" (art. 90.2, párrafo tercero del Código Civil) ${ }^{27}$.

En ambos casos deberán expresar la voluntad inequívoca de separarse y, además, determinar las medidas que hayan de regular los efectos de la separación en los términos establecidos en el art. 90 CC. La Ley de Jurisdicción Voluntaria, a través de la Disposición Final Primera, apartado 23, ha modificado también el art. 90 del Código

\footnotetext{
${ }^{25}$ Cf. Serrano de Nicolás, A. Ley de jurisdicción voluntaria. Aspectos de mayor relevancia notarial. La Ley 5060/2015.

${ }^{26}$ Cf. Serrano de Nicolás, A. Op. Cit.

27 Cf. Carrión Vidal. A. Divorcio y separación en el Código Civil tras la reforma de la 15/2015 de 2 de julio de la jurisdicción voluntaria. Instituto de Derecho Iberoamericano.
} 
Civil, referido al convenio regulador, señalando cuáles son los extremos que, en caso de ser aplicables, deberá contener el mismo. Recuérdese que la separación y divorcio ante Notario sólo cabe cuando los cónyuges no tuvieren hijos menores no emancipados o con la capacidad modificada judicialmente que dependan de ellos. En este sentido, es importante resaltar que, tal como dispone el art. 90.2, III, si al formalizar el convenio regulador ante el Notario, éste considerara que el acuerdo es dañoso o gravemente perjudicial para uno de los cónyuges o para los hijos mayores o menores emancipados afectados, lo tendrá que advertir a los cónyuges y dará por terminado el expediente, lo que implicará que el convenio regulador sólo podrá ser aprobado por un Juez. En este último caso, establece el art. 95.3 del Código Civil que las medidas que el juez adopte en defecto de acuerdo, podrán ser modificadas judicialmente o por nuevo convenio aprobado por el Juez, cuando así lo aconsejen las nuevas necesidades de los hijos o el cambio de las circunstancias de los cónyuges ${ }^{28}$.

Se desprende de los artículos 82 y 87 del Código Civil, que los cónyuges deberán intervenir en el otorgamiento de modo personal, es decir, no podrán actuar por medio de poder o representante. Se ha puesto de manifiesto que ya que en nuestro ordenamiento jurídico es posible el denominado matrimonio por poderes, no tiene sentido, que no sea posible también la separación o divorcio a través de apoderado ${ }^{29}$.

Además deberán de acudir los dos a la vez para firmar la escritura. Del tenor literal de los preceptos se desprende por tanto que los cónyuges tienen que concurrir ante el notario simultáneamente. En el ámbito de la separación o divorcio ante el Secretario Judicial según dispone el artículo 777.3 de la LEC la ratificación por los

\footnotetext{
${ }^{28}$ Cf. Pérez Cebadera. M A. La jurisdicción voluntaria: tramitación de matrimonios y divorcio ante notarios. La ley. 5184/2015.

${ }^{29}$ Cf. www.iurisprudente.com 2 de septiembre de 2015: "Pero parece que si cabe en nuestro derecho el matrimonio por medio de apoderado, no debería excluirse de modo absoluto la formalización notarial del divorcio o de la separación de igual modo. Sin embargo, la exigencia legal de que la intervención en estos actos sea personal impone ciertas limitaciones .En primer lugar, el poder debe ser especialísimo, recogiendo la voluntad de divorciarse o separarse y las cláusulas íntegras del convenio regulador que se incluirá en la escritura, limitándose el apoderado a actuar como un nuntius que transmite la voluntad plenamente formada del poderdante. Solo cumpliendo este requisito podría entenderse que se presta personalmente el consentimiento al divorcio o la separación, trasladándose la cuestión a si debe producirse dicho consentimiento con unidad de acto, lo que expresamente no se exige en el precepto. En ningún caso, un poder general para pleitos, aunque incluya actuaciones notariales, sería suficiente".
} 
cónyuges de la solicitud de divorcio o separación de mutuo acuerdo se prevé que obligatoriamente sea por separado ${ }^{30}$.

Todo ello sin perjuicio de que deban estar asistidos por letrado en ejercicio ${ }^{31}$, prestando su consentimiento ante el Secretario Judicial o Notario. Es decir, la intervención de letrado en ejercicio es obligatoria ${ }^{32}$. En el mismo sentido se expresa el artículo 54.2 de la Ley del notariado: los cónyuges deberán de estar asistidos en el otorgamiento de la escritura pública de letrado en ejercicio ${ }^{33}$. El informe del Consejo General del Poder Judicial sobre el Anteproyecto de la Ley, destacó la necesidad que las partes fueran asistidas por un letrado, pues, como se decía expresamente "el notario difícilmente podrá actuar a la vez, que como administrador del expediente, como asesor de cada una de las partes que reclaman su intervención”.

\footnotetext{
${ }^{30}$ Como se ha afirmado, sería también posible la intervención no simultánea de los cónyuges en la escritura de divorcio o separación, de manera que uno de ellos prestase su consentimiento con posterioridad al otro, ratificando la escritura de separación o divorcio, cuya eficacia habrá quedado condicionada a dicha ratificación o aprobación. Es cierto que el artículo 82 del Código Civil, como hemos dicho, contempla la intervención "personal" de los cónyuges en el acto de separación o divorcio y de su tenor general parece desprenderse que el legislador piensa en que los cónyuges concurran ante un solo notario y presten su consentimiento simultáneamente, no habiéndose previsto fórmula alguna de ratificación posterior, como sí hace la legislación procesal, ni contemplado las posibles consecuencias de esta forma de otorgamiento. Pero también cabe argumentar el precepto no impone la concurrencia simultánea de los cónyuges ni prohíbe expresamente que se otorgue el acto por apoderado o que se ratifique con posterioridad. Puede ser relativamente frecuente, además, que los cónyuges prefieran comparecer por separado ante el notario, y no deja de ser prudente respetar su voluntad al respecto en este tipo de situaciones personales, en las que casi debe darse por descontado el conflicto. De hecho, la ratificación por los cónyuges ante el Secretario Judicial de la solicitud de divorcio o separación de mutuo acuerdo se prevé que obligatoriamente sea por separado (artículo 777.3 LEC). www.iurisprudente.com .

${ }^{31}$ Con respecto a la necesidad de la asistencia letrada señala la Disposición Final Decimonovena, segundo párrafo, que cuando se solicite el reconocimiento del derecho para la asistencia gratuita en los casos de separación o divorcio ante Notario, la acreditación se realizará en la misma forma prevista en la Ley de Asistencia Jurídica Gratuita ante el Colegio Notarial, cuando alguno de los contrayentes sea beneficiario de la misma.
}

32. Si se solicitare el reconocimiento del derecho para la asistencia de Letrado en los casos de separación o divorcio ante Notario, la acreditación se realizará en la misma forma prevista en la Ley de Asistencia Jurídica Gratuita ante el Colegio Notarial.

${ }^{33}$ En definitiva, que el legislador quiere que la asistencia letrada, sin perjuicio de que pueda ofrecerse antes, exista siempre, y de modo personal, en el momento del otorgamiento de la escritura. Que a la hora de firmar la escritura de divorcio, los cónyuges mismos (y no unos representantes suyos) puedan consultar, hablar y negociar lo que sea preciso -en cuanto al convenio sobre todo- entre sí y asesorados por el abogado. En constancia de su presencia y asesoramiento legal, el o los letrados firmarán también la escritura. Cf. Goma Lanzón F. Divorcio de mutuo acuerdo ante notario: instrucciones de uso, http://hayderecho.com. 
El contenido del convenio regulador es el que determina el art 90 del Código Civil $^{34}$ : “1. El convenio regulador a que se refieren los artículos 81, 82, 83, 86 y 87 deberá contener, al menos y siempre que fueran aplicables, los siguientes extremos: a) El cuidado de los hijos sujetos a la patria potestad de ambos, el ejercicio de esta y, en su caso, el régimen de comunicación y estancia de los hijos con el progenitor que no viva habitualmente con ellos. b) Si se considera necesario, el régimen de visitas y comunicación de los nietos con sus abuelos, teniendo en cuenta, siempre, el interés de aquellos. c) La atribución del uso de la vivienda y ajuar familiar. d) La contribución a las cargas del matrimonio y alimentos, así como sus bases de actualización y garantías en su caso. e) La liquidación, cuando proceda, del régimen económico del matrimonio. f) La pensión que conforme al artículo 97 correspondiere satisfacer, en su caso, a uno de los cónyuges".

La separación matrimonial producirá sus efectos desde la manifestación del consentimiento de ambos cónyuges en el convenio regulador otorgado en escritura pública. Escritura pública que determina la suspensión de la vida en común de los cónyuges y cesa la posibilidad de vincular bienes del otro cónyuge en el ejercicio de la potestad doméstica (art. 83, I Código Civil). Se remitirá copia de la escritura pública al Registro Civil y, la separación no producirá plenos efectos frente a terceros de buena fe, hasta que se proceda a su inscripción. Los efectos de la disolución del matrimonio por divorcio por la formulación de convenio regulador en escritura pública se producirán desde el momento en que el que se otorgue ésta, de la que deberá remitirse copia al Registro Civil para que produzca plenos efectos frente a terceros de buena fe (art. 89 Código Civil) $)^{35}$.

\footnotetext{
${ }^{34}$ La Ley de Jurisdicción Voluntaria, a través de la Disposición Final Primera, apartado 23, ha modificado también el art. 90 del Código Civil, referido al convenio regulador, señalando cuáles son los extremos que, en caso de ser aplicables, deberá contener el mismo.

${ }^{35}$ Se ha puesto de manifiesto que las prisas en la redacción parece conduzcan a una cierta contradicción, por cuanto a "los efectos" de la separación se refiere, entre los párrafos primero y segundo del precepto en análisis, puesto que en el primero se alude "en abstracto" a unos efectos que se producen por la sentencia o decreto de separación o el otorgamiento de la escritura pública. Unos "efectos" que se producen ya, en tanto que en el párrafo segundo la producción de esos mismos efectos viene subordinada a "la firmeza de la sentencia o decreto que así la declare o desde la manifestación del consentimiento de ambos cónyuges otorgado en escritura pública". ¿Se demora, o no se demora, la producción de esos "efectos" a la circunstancia de que la sentencia sea firme, o lo sea el decreto o desde la manifestación del consentimiento de ambos cónyuges otorgado en escritura pública"? La cuestión quizá carezca de relevancia práctica cuando se trate de separación "de mutuo acuerdo" tramitada ante Secretario judicial o Notario, pero posiblemente sí la tenga cuando se trate de separación judicial, puesto que en tal caso, y
} 
De esta forma, puede observarse que los efectos de la separación o el divorcio se producen desde el mismo momento en que se presta el consentimiento en la escritura pública, no precisando acto posterior alguno, lo que no ocurre en la separación formalizada ante el Secretario Judicial, en la que se exige una resolución posterior que se pronuncie sobre el mismo ${ }^{36}$.

Los efectos serán idénticos al divorcio judicial: Se extingue el vínculo matrimonial (pudiendo contraerse nuevo matrimonio). Cesa la obligación y la presunción de convivencia de los cónyuges. Se extingue el régimen económico del matrimonio. Quedan revocados todos los consentimientos y poderes que un cónyuge hubiera concedido al otro. A diferencia de la regulación anterior en la que, al menos de modo expreso y por cuanto a la separación se refiere, no se hacía referencia a la inscripción de la sentencia en el Registro Civil, en la nueva redacción el párrafo segundo, inciso final del art. 83 establece que: "Se remitirá testimonio de la sentencia o decreto, o copia de la escritura pública al Registro Civil para su inscripción, sin que, hasta que esta tenga lugar, se produzcan plenos efectos frente a terceros de buena fe".

Si la separación se acordó en escritura pública ante Notario y se produce la reconciliación, ésta deberá igualmente formalizarse en escritura pública, que también

ateniéndonos a la literalidad de la norma, habría que esperar al carácter firme de la sentencia para entender "producidos" esos efectos, firmeza del fallo para cuya obtención deberá transcurrir un periodo de tiempo (siquiera sea breve), durante el cual habría que entender aun "no producidos" los susodichos efectos. Cuando la separación, como se ha dicho, se tramite ante Secretario judicial igualmente deberá ser "firme" el decreto expedido por aquél que la declare, y finalmente, cuando lo sea ante Notario la "producción” de esos efectos tendrá lugar "desde la manifestación del consentimiento de ambos cónyuges otorgado en escritura pública". También en este supuesto, la dicción legislativa no deja de plantear dudas o interrogantes, porque mientras en el párrafo primero se habla del "otorgamiento de la escritura pública del convenio regulador", en el párrafo segundo el legislador se refiere a "la manifestación del consentimiento de ambos cónyuges otorgado en escritura pública”. ¿Acaso cabría diferenciar aquí dos realidades, o dos momentos, plenamente diferenciadas, subordinando la "producción" de los efectos a que acontezca la segunda de ellas? ¿Hasta qué punto sería "separable” la fase de "otorgamiento de la escritura pública del convenio regulador", de la referida a "la manifestación del consentimiento de ambos cónyuges otorgado en escritura pública”? ¿Cabría un "otorgamiento de la escritura pública del convenio" separada de "la manifestación del consentimiento de ambos cónyuges otorgado en escritura pública"? Sea de ello lo que fuere, diríase que el propósito legislativo fuere efectivamente el de diferenciar dos "fases" o "etapas" cuando la separación se tramite ante Notario, distinguiendo la fase misma del otorgamiento, y un momento ya posterior, concluyente, en el cual el consentimiento de los cónyuges se proyecte ya sobre el contenido del documento redactado por el Notario. La "producción" entonces de los efectos de la separación arrancaría de este segundo. Cf. Carrión Vidal. A. Divorcio y separación en el Código Civil tras la reforma de la 15/2015 de 2 de julio de la jurisdicción voluntaria. Instituto de Derecho Iberoamericano

${ }^{36}$ Cf. Pérez de Ontiveros Baquero, C. Separación y divorcio matrimonial: una lectura inicial tras la modificaciones introducidas por Ley 15/2015 de jurisdicción voluntaria. Aranzadi Civil- Mercantil número 10/2015. 
deberá inscribirse en el Registro Civil para que tenga eficacia ante terceros (Art. 84 del Código Civil.). Sin embargo, la simple notificación de la reconciliación al Notario que otorgó la escritura de separación, hace que el cónyuge sobreviviente conserve los derechos sobre la herencia en caso de fallecimiento del otro (Art. 835 del Código Civil). Como el divorcio supone la disolución del matrimonio, la reconciliación posterior de los cónyuges no tiene efectos legales, sin perjuicio de que los divorciados puedan contraer entre sí nuevo matrimonio (Art. 88 del Código Civil).

Como se puede ver pocas diferencias supone el nuevo texto del artículo 84 con respecto de la redacción anterior. La coincidencia del texto es total y absoluta por cuanto se refiere al párrafo primero, precisando ahora el segundo que "Cuando la separación hubiere tenido lugar sin intervención judicial, en la forma prevista en el artículo 82, la reconciliación deberá formalizarse en escritura pública o acta de manifestaciones", añadiendo el párrafo tercero y último que "La reconciliación deberá inscribirse, para su eficacia frente a terceros, en el Registro Civil correspondiente". Nada nuevo, pues, en lo atinente a este último párrafo. La necesaria inscripción de la reconciliación se infería (aun sin formulación expresa) de la anterior regulación, dada la exigencia de "ponerla en conocimiento del Juez que entendiera o hubiera entendido en el litigio".

De otra parte, y tratándose de separación tramitada ante Secretario judicial o Notario, la reconciliación deberá venir formalizada, como se ha dicho, en "escritura pública o acta de manifestaciones". Es de suponer que la opción de los cónyuges por una u otra estará en función, muy probablemente, del coste respectivo que deban sufragar. De otra parte, mientras el otorgamiento de la escritura pública corresponderá, exclusivamente, a los Notarios, el "acta de manifestaciones" podrá formalizarse por comparecencia de los cónyuges ante Notario, o ante Secretario judicial. Y, obviamente, en ambos casos, el Notario que proceda al otorgamiento de la escritura (en su caso, del acta) o el Secretario ante el cual se formalice el acta, podrán ser, o no, aquéllos ante los cuales se tramitó la separación.

Es decir, podríamos preguntarnos si al hacer la separación ante notario necesariamente la reconciliación tiene que hacerse también ante notario o si es independiente ante quien se haya llevado a cabo la separación a la hora de elegir ante 
quien se quiere llevar a cabo la reconciliación si ante el notario o ante el secretario judicial indistintamente.

Es novedosa la intervención de los hijos mayores o menores emancipados mediante la prestación de su consentimiento: "deberán otorgar el consentimiento ante el Secretario judicial o Notario respecto de las medidas que les afecten por carecer de ingresos propios y convivir en el domicilio familiar". Se exige pues que el divorcio sea consentido por los hijos mayores o menores emancipados que convivan en el hogar familiar por carecer de ingresos propios; medida que a nuestro juicio requiere un mayor y mejor desarrollo. Este consentimiento es esencial, si no se presta no hay aprobación de convenio ni tampoco divorcio. Por ello, deberán estar presentes en el momento de otorgar la escritura, aunque la ley no exige su presencia personal, de modo que podrían estar representados por apoderado ${ }^{37}$.

Es decir, que aunque el divorcio sea de mutuo acuerdo entre los padres, los hijos mayores de edad - que, en principio, son ajenos al divorcio- si conviven en el domicilio y carecen de ingresos propios deben consentir el divorcio de mutuo acuerdo de los padres por un supuesto derecho de alimentos que les corresponda ${ }^{38}$.

Y debemos preguntarnos ¿pueden los hijos cercenar la libertad de los padres? ¿No sería más razonable que en caso que las medidas propuestas resultaran perjudiciales para los hijos fuera el juez quien decidiera? Además no olvidemos que el precepto exige que se trate de mayores de edad o menores emancipados.

\footnotetext{
${ }^{37}$ Así lo establece el artículo 82.1 del Código Civil. El art. 54 LN no dice nada respecto de los hijos mayores de edad. Y el art. 90.2 C.C. señala que cuando el Notario considere que, a su juicio, los acuerdos de los cónyuges pueden ser dañosos para los hijos mayores de edad afectados lo advertirá a los otorgantes y dará por terminado el expediente. Así pues, parece que los hijos mayores de edad deberán prestar su consentimiento a la escritura de separación o divorcio de mutuo acuerdo de sus padres salvo que se acredite que no viven en el domicilio familiar o que aun viviendo en el domicilio familiar tienen ingresos propios.

${ }^{38}$ En este sentido, el art. 90.2 C.C. dispone que si el Notario estimara que los acuerdos de los cónyuges pudieran ser dañosos o gravemente perjudiciales para los hijos mayores o menores emancipados afectados - que convivan en el domicilio conyugal y carezcan de ingresos propios - lo advertirá a los otorgantes y dará por terminado el expediente, lo cual es tanto como decir que no se autorizará la escritura de divorcio de mutuo acuerdo.
} 
Esta previsión, que no tiene correspondencia en el marco del homólogo procedimiento judicial, debe ponerse en relación, a su vez, con la previsión del art. 93.4 $\mathrm{CC}$, de acuerdo con el cual, "si convivieran en el domicilio familiar hijos mayores de edad o emancipados que carecieran de ingresos propios, el Juez, en la misma resolución, o los progenitores en la escritura pública en la que formalicen el convenio, fijaránlos alimentos que sean debidos conforme a los artículos 142 y siguientes". El actual art. 93.II CC dispone únicamente que "si convivieran en el domicilio familiar hijos mayores de edad o emancipados que carecieran de ingresos propios, el Juez, en la misma resolución, fijará los alimentos que sean debidos conforme a los artículos 142 y siguientes de este Código". La finalidad de esta norma es mejorar la economía procesal, permitiendo que en el proceso matrimonial se resuelva la cuestión de los hijos mayores, a fin de evitar que el legitimado deba reclamarlos en un proceso aparte. Se admite que este derecho de alimentos, por ello, sea reclamado en el proceso matrimonial por el cónyuge con el que pasan a convivir los hijos mayores, en una suerte de legitimación por sustitución que ha sido avalada por la jurisprudencia ${ }^{39}$

¿Qué ocurre en el caso que los hijos sean mayores de edad y conviven en el hogar familiar por su propia voluntad teniendo ingresos propios? Se desprende del tenor literal del artículo que habiendo hijos mayores o emancipados, pero con recursos o ingresos propios y que sigan conviviendo en el domicilio familiar, no es necesario que presten su consentimiento.

El tema de los hijos nos presenta distintos interrogantes, ¿Hablamos de hijos de uno, de otro o comunes del matrimonio? La configuración de la familia en la actualidad excede con mucho al concepto clásico de matrimonio con hijos comunes.

¿Y si el hijo común, o de uno, o del otro, decide bloquear la decisión libre y voluntaria de la pareja? Bastante difícil resulta a veces llegar a un acuerdo mutuo entre los cónyuges como para introducir los intereses personales de uno o varios hijos. En un procedimiento judicial, los hijos menores deben ser oídos y defendidos por el Fiscal, pero en la Ley de Enjuiciamiento Civil (Artículos 778 y siguientes LEC, en relación con el 90 del Código Civil) no hay audiencia prevista para los hijos mayores.

\footnotetext{
${ }^{39} \mathrm{Cf}$. Informe CGPJ anteproyecto de ley de jurisdicción voluntaria.
} 


\section{Bibliografía Básica Recomendada}

- BANACLOCHE, PALAO. J La intervención de abogado y procurador en la nueva ley de jurisdicción voluntaria. La Ley 503372015.

- CALAZA LÓPEZ, S. Una nueva jurisdicción voluntaria de personas y de familia (1) Práctica de Tribunales, № 116, Septiembre-Octubre 2015, Editorial LA LEY LA LEY 5178/2015

- CARRIÓN VIDAL. A. Divorcio y separación en el Código Civil tras la reforma de la 15/2015 de 2 de julio de la jurisdicción voluntaria. Instituto de Derecho Iberoamericano.

- CAVAllÉ CRUZ, A. Viabilidad del divorcio del mutuo acuerdo ante notario. EL NOTARIO DEL SIGLO XXI - MARZO-ABRIL 2012 / N42

- ESPINOSA DE SOTO, J.L. Tendencias actuales en derecho de familia. Escritura pública. Número 95 septiembre-octubre de 2015.

- FERNÁNDEZ DE BUJÁN A. La Ley de jurisdicción voluntaria en el umbral de su aprobación Actualidad Jurídica Aranzadi num 90818 de junio de 2015.

- GOMA LANZÓN F. Divorcio de mutuo acuerdo ante notario: instrucciones de uso, http://hayderecho.com.

- LUDEÑA BENÍTEZ. O.D. Alternatividad o exclusividad de profesionales en la tramitación y decisión de los expedientes de jurisdicción voluntaria: una discusión parlamentaria y doctrinal hasta la aprobación de la Ley 15/2015, de 2 de julio. Práctica de Tribunales, No 116, Septiembre-Octubre 2015, Editorial LA LEY. La Ley 185/2015.

- PÉREZ CEBADERA. M A. La jurisdicción voluntaria: tramitación de matrimonios y divorcio ante notarios. La ley. 5184/2015.

- PÉREZ DE ONTIVEROS BAQUERO, C. Separación y divorcio matrimonial: una lectura inicial tras la modificaciones introducidas por Ley 15/2015 de jurisdicción voluntaria. Aranzadi Civil- Mercantil número 10/2015.

- RIVERO SÁNCHEZ COVISA. F.J. La intervención del notario en el matrimonio conforme a la nueva ley de jurisdicción voluntaria. Revista Bimestral del Ilustre Colegio Notarial de Madrid 10 de julio de 2015.

- ROSALES DE SALAMANCA RODRÍGUEZ. F. ¿Divorcio ante notario habiendo hijos menores? Mayo 2015. 


\section{Revista Internacional de}

\section{Doctrina y Jurisprudencia}

- SÁNCHEZ GARCÍA J.M. La alternatividad entre los letrados de la administración de justicia, notarios y registradores, en los supuestos de separación o divorcio de mutuo acuerdo, obligaciones y expedientes de conciliación, en la ley de jurisdicción voluntaria. Revista de Derecho v Lex Núm.136, Septiembre, 2015

- SERRANO DE NICOLÁS, A. La ley de jurisdicción voluntaria: aspectos de mayor relevancia notarial. La Ley 5060/2015. 